\title{
FESTSCHRIFT
}

\section{The virtues (and vices) of the four principles}

\section{A V Campbell}

Despite tendencies to compete for a prime place in moral theory, neither virtue ethics nor the four principles approach should claim to be superior to, or logically prior to, the other. Together they provide a more adequate account of the moral life than either can offer on its own. The virtues of principlism are clarity, simplicity and (to some extent) universality. These are well illustrated by Ranaan Gillon's masterly analysis of the cases he has provided. But the vices of this approach are the converse of its virtues: neglect of emotional and personal factors, oversimplification of the issues, and excessive claims to universality. Virtue ethics offers a complementary approach, providing insights into moral character, offering a blend of reason and emotion, and paying attention to the context of decisions. The cases provided can be more adequately understood if we combine the approaches. Both should foster the virtues of humility and magnanimity.

n this paper I want to explore the relationship between the four principles approach, advocated by Raanan Gillon, and virtue ethics, an alternative approach to medical ethical issues, which has influenced my thinking in recent years. For an account of some recent research using this approach see my article with Teresa Swift, What does it mean to be a virtuous patient. ${ }^{1}$ I want to avoid simplification of either approach and I eschew any attempt to "prove" that one is preferable to (or logically prior to) the other. Instead, I shall first consider in a general way the main features of virtue ethics, discuss, again in general terms, how the relationship between such areteic theories and deontic theories like principlism can be structured, and end with the application of these general points to the cases selected by Raanan. ${ }^{2}$ The terms "areteic" (based on virtue or character) and "deontic" (based on duty or obligation) are convenient shorthand terms for the two approaches, used by D Statman in Virtue Ethics: a Critical Reader.

Correspondence to A V Campbell, Centre for Ethics im Medicine, University of Bristol 73 St Michael's Hill, Bristol BS2 8BH, UK; alastair.campbell@bristol. ac.uk

Accepted for publication 25 June 2003

\section{HOW SHOULD ONE LIVE?}

The title of Crisp's collection of essays on virtue ethics (VE) usefully encapsulates the approachHow should one live? ${ }^{4}$ Instead of focusing on moments of decision, on the dilemmas of action in our morally complex world, VE stresses the character of the moral agent. The famous declaration of Socrates that "examining both myself and others is really the very best thing that a man can do, and ... life without this sort of examination is not worth living" ${ }^{\prime 5}$ can be seen as one example of a commitment to live one's life in a particular way, a commitment which, of course, has its consequences in specific actions. (In the case of Socrates the refusal to renounce his views at his trial and subsequent refusal to escape from Athens, resulted in his death.) Moreover, VE encompasses more than rational choice. It is concerned with that amalgam of reason and emotion, which is required in order to live consistently within one's moral commitments. The blend of intuition, reasoned choice and empathy for one's fellow humans is perhaps best captured by Bellah's phrase, "habits of the heart". ${ }^{6}$

Such habits are not, of course, naturally present in us from birth. They are acquired as one matures in age and experience, and are the product of a range of influences, including parents and peer groups, education, cultural influences, and exemplars of good character in people we admire and seek to emulate. Traditionally, religion has been a potent influence in the formation of character, and clearly it continues to be so in many cultures today. But, alongside these theocratic cultures, are the pluralist, secularised, and expansionist societies of the modern West. As a result-as any advocate of VE should be quick to admit-we have a bewildering variety of images of "the good life", many of them deliberately manipulated for commercial gain. (I have explored this issue in my book, Health as Liberation. ${ }^{6}$ ) Thus VE, in its attempts to stress not just morally justifiable decisions but morally admirable character traits, has to struggle with a major problem of cultural relativism. Which images of the good person or the good life are the normative ones? And how does VE justify such a claim in face of a bewildering variety of some images, many of them mutually contradictory? (An obvious example would be views of the nature of marriage and the role of women in traditional Islamic cultures and in modern Western ones.) Does this problem represent a fatal flaw in VE? I think not, but I will delay discussion of this issue to a later section. For the present, it is interesting to note that advocates of the four principles seem to believe that the principles transcend such cultural differences. ${ }^{8}$ We shall see that it is not as simple as that.

\section{CONFLICT OR COMPLEMENTARITY?}

I turn now to the question of how the VE approach might relate to deontic theories, those approaches which stress choice, decision, and action. Different authors in VE have adopted variant views of this relationship. Statman ${ }^{3}$ provides a useful description of the range. Moderate approaches to VE regard it as complementary to action based approaches: virtue cannot be subsumed under the notion of following moral rules. 
It has its distinctive place in a full understanding of morality. But this full understanding equally requires an account of rule based universal obligations. By adding judgments of character to judgments of right action we get a richer account than either offers separately. Radical approaches to VE do not accept this complementarity: judgments of character are always seen as prior to judgments of action. In reductionist radical VE the force of statements of rightness or obligatoriness is derived from their source in the actions of a virtuous character; in replacement radical VE deontic statements are rejected altogether-they may even have a pernicious effect on morality. In this most radical approach all that counts is the presence or absence of virtue. (Alasdair MacIntyre's total rejection of the post-Enlightenment project in After Virtue could be seen as a powerful example of this replacement approach. ${ }^{9}$ )

It may appear at first that the advocates of the four principles would be sympathetic to some form of complementarity, as represented by the moderate approaches to VE. In the latest edition of their influential book, Beauchamp and Childressfor example, offer what they call a "constructive evaluation of character ethics", and they do concede that ethical theory may be more complete if the virtues are included. ${ }^{10}$ They reject the idea, however, that virtue can be the prior measure of morality: "It is unacceptable to claim that if persons display a virtuous character, their acts are therefore morally acceptable" (see reference 10, p 68). In similar vein, Raanan, in his editorial commentary on a paper of mine in Principles of Health Care Ethics, while conceding that character traits which tend to promote good attitudes and behaviour or discourage bad ones are "a crucially important aspect of morality", ( see reference 8, p 331) nevertheless insists that our source of judgment about such traits as virtues or vices has to be the four principles or some such. Here is how Raanan puts it:

Descriptions, such as wise, brave, tolerant, persevering, dependable, sincere, loyal, humorous, humble, open, warm, are all character descriptions. But whether or not they are to be described as virtuous will surely depend on the extent to which they tend to produce morally desirable attitudes and behaviour ... whether or not they tend to respect autonomy, be beneficial, avoid harming, and be just (see reference 8, p 330).

I must conclude from this that the complementarity, which is acceptable to advocates of the four principles is very different from that sought by moderate VE approaches. Notice that for the moderate VE approach, judgments of character form part of the content of morality - they are not derivative from an acceptance of some set of deontic imperatives, but complementary to them. But for Raanan Gillon and his American colleagues this is asking too much. For them virtues can be specified only if we accept as logically prior the principles they advocate. To explore this difference further, let me take an example, which Raanan uses to make his point: the conscientious Nazi.

\section{THE CASE OF THE SINCERE ETHNIC CLEANSER}

In the discussion of my paper referred to above, Raanan argues that my list of character traits, such as tolerance, sincerity, courage, and perseverance, may be described as either virtuous or vicious, depending on the attitudes and actions of the person to whom they are applied. So-for example, Eichmann may well have been sincere, persevering, and even courageous in his determination to ensure the gassing of his Jewish victims. The virtuous or vicious nature of such character traits can be determined only by filling in the moral context of their implementation in action or by evaluating the attitudes, which they support. Thus to condemn Eichmann VE needs the four principles.
Now, obviously, no ethical theory can afford to be accused of condoning, or even praising, ethnic cleansing, but Raanan's argument here depends on grossly simplifying VE. (It may be a justified criticism of my account in the chapter to which he refers, but the main task of that chapter was not to expound VE, but to emphasise the importance of ideals in medicine.) No account of VE that I know of merely reels off a list of character traits. From Aristotle onwards, the virtues are set within an account of human nature. In Aristotle-for example, the concept of the intellectual virtues, of practical wisdom and of eudaemonia are key, while for Aquinas the goal of human flourishing provides a unified account of humanity in community. Other theological accounts, deriving from biblical sources, put agape (a combination of reason and emotion in the service of others) in a prime position. These are all unified accounts of the nature of virtue, and none could countenance as virtue a dedication to the murder of fellow human beings. Perhaps it is important to re-emphasise here the features of VE that stress both reason and emotion and set the virtues within a communal and temporal frame.

Of course, Raanan and his fellow critics could now object that I have imported more than simply virtue into the reckoning. I have added some kind of framework for the integration and ordering of the virtues. Is this not just what he and the others refer to when they say that VE is deficient, without recourse to the four principles? I would respond that it is no more deficient than the four principles themselves, for, as the advocates of that approach readily concede, the principles do not contain within themselves a criterion for ordering, if they conflict. What then is the defence against putting autonomy first for Eichmann and letting him proceed, despite the manifest maleficence and injustice of his actions? Any such defence must appeal beyond the principles to some unifying theory.

I conclude that VE and the four principles are "partners in crime" when it comes to the final justification of our moral intuitions. Each captures different dimensions of our moral universe, but one is not better than the other in settling finally how we make correct moral judgments. The principles help us to structure our reasoning when faced with novel moral challenges and they remind us of key questions to be explored. Virtue ethics directs us to the character of the decision maker, but also to the implications for our whole lives and for society of individual choices and policy decisions. This is, however, somewhat abstract. It is time to turn to the cases to see how VE might differ in its conclusions from those drawn by Raanan on the basis of the four principles.

\section{CASES, PRINCIPLES, AND VIRTUES}

I must preface this section by pointing out that the case scenarios offered by Raanan create an immediate problem for VE. ${ }^{2}$ In common with many case descriptions in medical ethics, they are merely paradigmatic, not case histories in any genuine sense. For the four principles approach this kind of minimalistic description is all that is required. Indeed, as Raanan, himself argues, for his approach, unreal cases, such as thought experiments, are often more useful, since they bring out the general features of ethical principles in strong relief. But the paucity of description leaves little for the VE theorist to reflect upon-and the same problem would surely affect other non-principle approaches, such as narrative ethics, feminist ethics, and communitarian ethics.

So, to grapple with the cases I need to set them in a richer context. I shall do this by referring to a seminal article by Martha Nussbaum, entitled "Non-relative virtues: an Aristotelian approach". ${ }^{11}$ Nussbaum is confronting the problem of cultural relativity in accounts of virtue-for example, some of Aristotle's writing seems to assume that virtue is to be equated with the mores of powerful and cultured Athenian males. Despite these difficulties, Nussbaum argues that we can identify a set of non-relative virtues, which relate to universal 
aspects of human experience, such as birth, love, illness, and death. These virtues cohere in a general understanding of human flourishing, but just how they will be expressed in practice will vary according to cultural and historical circumstances-an obvious example will be differing attitudes to illness and death. Thus there are universal virtues, but they are "thin", basic forms of human attitudes to non-optional events. They acquire "thickness" according to their social and cultural context and so we may reasonably expect variation from society to society and epoch to epoch. This variation, however, does not prevent us from asking whether the particular cultural form aids or inhibits human flourishing. Hence we may criticise alleged virtues if - for example, they encourage disregard of particular social groups.

I shall use Nussbaum's description of virtues as human attitudes to non-optional events as a way of speculating (in the absence of much detail) about the background to the cases chosen by Raanan. ${ }^{2}$

\section{The Jehovah's Witness cases}

Clearly these cases provide an arena for Nussbaum's idea of attitudes to non-optional events. Both entail confrontation with the high likelihood of death, but, in addition, the second adds another central human experience, the dilemmas of parenthood. Gillon's handling of the cases is cool and objective (as befits a person dedicated to principled analysis), and it is hard to fault his conclusions. ${ }^{2}$ Current ethical and legal practice is to accede to the refusal of life saving treatments by competent adults, but to intervene to save the lives of children, when parents are seen to be acting against their best interests. But the paucity of detail and the coolness of the analysis mask the moral ambiguities of real cases of this kind. The first case is presented as an example of non-interference in a competent person's autonomy, as though that is all there is to be said. But Jehovah's Witnesses do not actively seek to die (that would be a sin in their religion), and often they struggle very hard to remain true to their faith group's teaching. What if we add some more detail-say, that this competent adult is also the father of young children and his earnings are critical for adequate support for his wife and family? This immediately shifts the case from a straight question of autonomy, to whether autonomy should trump non-maleficence and (perhaps) justice. But if Raanan believes that it should, what is his moral justification for this lexical ordering of the principles? (I would be interested to know how Raanan answers this, in light of his consistent statements that the principles are in no particular order.)

A VE approach could well come to the same conclusion, but after a very different kind of analysis. We need to know more about the character of this patient and his manner of facing this terrible crisis in his life. (I have argued for some time that we need a more patient orientated medical ethics, and that VE could well be a good vehicle for this. ${ }^{12}$ ) There is no doubt that for the patient the key question is, what kind of life should I live? As a Jehovah's Witness he sees his life as having value only if it is lived in total obedience to God's will, as he understands it. So to survive, after the "corruption" of a blood transfusion, must be seen as worse than death. Yet (if you will allow me the extra detail I have suggested) to die, abandoning wife and children, when he could have his life saved, is also a dreadful dereliction of duty. (It is small wonder that some Jehovah's Witnesses silently collude in an "accidental" transfusion.) It simply will not do to discuss the harms and benefits merely in relation to this patient as an isolated individual-in virtually any death that could have been avoided there must be harm to those who love or depend upon the person and to those who care for them. (Our liberal attitudes to suicide often overlook this.)

Perhaps Raanan is right that for the professional staff involved the moral imperative is to respect the patient's autonomy, but again there needs to be more attention paid to the effect that such stepping back must have on the staff, for whom the patient's beliefs are simply incomprehensible. ${ }^{2}$ In light of this, I do not see why the staff, if they have the opportunity, should not share with the patient their distress and puzzlement at his choice of likely death. If we focus on character and not just on decision, then we could see this as a richer respect for the patient than merely standing back. Paradoxically a truly dedicated Jehovah's Witness will welcome this last chance to witness to his faith and to share the manner of his death with those who might want to learn more about why he believes so strongly. (I recognise that some of this is highly unlikely given the acutely ill state of the patient.)

In summary, then, a VE approach would want to explore the consistency of both the patient's and the staff's actions with their understanding of themselves as moral agents, with their own goals and commitments. The courage, perseverance, and wisdom of the patient has to be the centre of attention, and we need to know that his choice, especially if it entails damage to a family, is true to the life he seeks to lead. For the staff, there is a clear conflict between what the patient requests and what their professional commitment requires. This is not, therefore, a straightforward and painless decision for them. For this reason, I prefer to see the moral obligation on them as "respect for the person", not the more distant sounding "respect for autonomy". Respect for the person entails dialogue, perhaps even confrontation, but only to ensure an honesty in each party, in the face of death. We need VE-and not as an optional extra-because by its nature it asks both how shall I live and how shall I live with mortality, the inevitability of death?

Of course, when a 2 year old child is involved, the parameters shift. Now the law can be used to ensure the appropriate treatment, and the actions of the parents in jeopardising their own child's survival for the sake of their beliefs are even harder to understand. Once again, however, it is hard to see this as a "standard" case. Experience suggests there is no such thing, and that the views of parents and even the advice they receive from their church officials varies a great deal. (One hears anecdotal evidence that suggests some parents hope to be overruled, and it may even be that the Jehovah's Witness community is beginning to revise the doctrine. ${ }^{13}$ ) But let us imagine a scenario in which the parents are quite convinced that for their child to survive with "tainted" blood is a fate worse than death, and that they anticipate that such a surviving child will never be acceptable to them or their community.

In this toughest of possible scenarios, we have to settle on one moral vision as normative-and here, I think, the four principles or some similar deontic approach has more to offer than VE. (A parallel example would be parents convinced that, for her own welfare, their daughter had to be radically "circumcised".) The problem is that the concept of the good parent is seen utterly differently by the parents and by the professional staff (and the vast majority in our society). We should give the parents the credit of seeing that this must be an agonising situation for them (but one they must have foreseen, given their beliefs). They honestly believe the transfusion will harm their child irreparably and so they must have the courage and perseverance to oppose it and risk their child's death. Such parents will not be relieved by a court order requiring the transfusion. Everything we might say about the virtue of parenthood, in terms of love and care for their child, will be seen by them as reinforcing their decision to oppose transfusion. The staff, on the other hand, cannot be true to their convictions about their moral duty, if they stand back and agree with the parents. The four principles approach resolves this dilemma, by arguing that the autonomy of the parents is strictly bounded by their obligation to promote the welfare of their child, and that in this case their assessment of the balance of benefits and harms is mistaken. 
I do not think the VE approach has the kinds of conceptual tools required to make such a judgment, and in this respect it may be more vulnerable to relativism than those theories which appeal to widely held general moral principles. I think we should note, however, that the assessment of benefits and harms (when not able to be made by the individual him or herself) is notoriously difficult. (A good additional example of this are judgments about which infants have "unbearable" handicaps.) The four principles alert us to the need to make such judgments, but they do not contain within themselves the means of doing so. We are left eventually (as Raanan admits) with an appeal to the common modern view of what constitutes clear harm. In this view, since there is no damnation and no eternal soul, death must be a greater harm than the alleged corruption of a person's soul. This has to be an unjustified basic moral assumption, for, it defies either proof or disproof; and, since many societies in the past and some in the present hold it to be otherwise, perhaps we need to accept that it is culturally relative.

\section{The policy scenarios}

Raanan's second two scenarios are of a different kind. ${ }^{2}$ Rather than presenting individual cases, even in outline, he describes two possible policy changes, one in respect of the sale of kidneys for transplantation and the other in respect of germline modification.

I can hardly complain about the lack of personal detail in these scenarios, since they are not about any specific person, but about what our societies should or should not permit. My difficulties with these scenarios do not relate so much to problems with autonomy or with the harm principle as such, though these are both relevant. My main concern is with an apparent collapsing of the notion of justice into these other principles. My own understanding of the principle of justice is that it relates not just to questions of liberty and the prevention of harm to individuals, but also to specific provisions for protecting the vulnerable and to the furtherance of equality. Now, of course, my account is open to debate (though I can claim some quite respectable bedfellows, such as Rawls), but I do not want to elaborate it here. Instead I want to suggest that VE would focus on these aspects of justice in considering the policy issues chosen by Raanan. Such a focus requires us to think more about the values enshrined in and promoted by our society, and less about non-interference with commerce and with scientific innovation. It is, to use a word referred to by Raanan, precautionary in approach-conservative even!

\section{On selling bits of your body}

Raanan rejects selling kidneys for transplantation, not on principle (any of the four) but on purely consequentialist grounds: the dangers of exploitation of the poor, the risks of infection, and the likely reduction in volunteers, thus removing one valuable source of organs. This is not an objection in principle by Raanan, since he sees no inherent harm in the practice, nor any threat to either justice or autonomy. Thus, if his predictions of bad consequences proved unfounded, he would have no moral objection to kidney sales.

A VE approach to this issue would turn to a different range of concepts. Firstly, we recall that VE is integrative in approach, seeing the moral life as a blend of reason and emotion. Such an approach inevitably entails an embodied view of the self-not the "ghost in the machine" of Descartes, but the thinking animal of Aristotle. This means that, for VE, dismantling my body (though within the boundaries of likely survival) in order to earn money raises some serious issues about personal integrity, since I am treating part of myself as a permanent and alienable commodity. Of course, the permanent transfer of part of one's body to another is what every donor does-whether that be bone marrow, blood, sperm, ova, or a whole organ for transplantation. But in these cases, the act is usually one of giving to unnamed strangers who are known to be in need. The character of the act of bodily alienation is altered by this fact. Equally, the gift of an organ to a friend or relative represents an act of self giving in a way that a commercial transaction does not. (I might sell my car to my daughter quite appropriately, but if I also charged her money for my kidney or my blood, something would seem to have gone awry in the relationship!) Tom Murray expresses the personal and social significance of such gifts as follows:

One of the ways to express solidarity with "strangers" is by contributing to the satisfaction of basic human needs and desires.... Relying on this system fulfils many of the social values mentioned earlier as justifications for gift exchanges. They include expressing solidarity in the face of illness and suffering, and declaring respect and support for biomedical research and teaching. ${ }^{14}$

Thus the human flourishing perspective of VE, which includes the individual commitment to moral ends and the building up of social relationships, would see a policy of kidney sales as counter to virtue. Allied to this objection is the problem of equality. The commitment to equality and protection of the vulnerable, which I mentioned earlier as key features of justice theory, result in an objection to the inherent inequality of organs sales. It is not accidental that the poor are the sellers and the rich the purchasers of such commercially obtained organs. It is simply inconceivable that a rich person would as readily sell her kidney as her BMW, though the price could be similar. Only a person already desperate for the necessities of life for self or family would contemplate selling an irreplaceable part of the body to make some temporary income. Thus the introduction of a market would lead to even greater inequality in health prospects of the rich and the poor, and therefore enshrines in social arrangements an inherent injustice. We recall that VE argues that our social environment is a potent force in the formation of those "habits of the heart" we call virtues. Thus a social arrangement which legitimises inequality must be seen as destructive of virtue.

\section{Enhancing the germline}

I find the second policy issue more difficult to relate to VE, since it contains to so many unknown factors. It is here that Raanan resorts to a thought experiment in an attempt to calculate the balance between non-maleficence and beneficence in germline modification. The advantage of a thought experiment is that you can fix the values in any way you like. Since the situation is purely hypothetical, you do not need to trouble yourself with calculating likely outcomes. Let me try another thought experiment in response. Suppose it were established beyond doubt that the SARS virus has been transmitted from some cattle in southern China, and that it poses an ever increasing threat to human survival on this planet, because of its capacity to mutate rapidly once it infects humans. Thus every vaccination and every treatment has a temporary effect, buying only a little time before a new mutation defeats these efforts at control. Then one inventive scientist hits upon an ingenious solution. He has observed that the virus in the cattle, though causing some temporary sickness, is self limiting and does not mutate as it does in humans. In addition, genetic engineering has advanced to such an extent that he knows how to produce a herd of cattle that would retain this immunity, but, due to the addition of human genes, would have the intelligence level and range of emotions of humans. They would, however, still look like cattle, and would have all the disadvantages of hooves compared with finger/thumb opposition. As he contemplates the rapid extinction of the human species as we know it, should he create some humanised cattle, to ensure at least some strange survival of human history 
and culture? If he does try to do this, should there be policy and the force of law to stop him?

I accept that my thought experiment is much more fantastical than Raanan's, but then who has written the rules for thought experiments-by their nature they are experimental. So can we calculate the benefits and harms resulting from ensuring the survival of at least a few humanised cattle? It might be fun to try to do so, but clearly it can't be done, because there are too many unknowns. Will the cattle be miserable in their bulky shapes and suffer grievously from their knowledge of what human life and human dexterity was like, passed on to them before the deaths of the few remaining humans? Or will they find some idyllic vegetarian and pastoral existence in a culture we can only dimly imagine? We cannot possibly say, but, assuming they are fertile and capable of survival without human aid, we do know that, for good or ill, humanised cattle will be the new form of human existence the scientist has created.

Are we significantly safer in our predictions of harm and benefit from Raanan's experiment? I would argue that we are not. We cannot be sure of future outcomes through the successive generations, which would be affected by our germline modification, but we can be sure of the exponential spread of whatever good or ill we create. AIDS provides a good illustration of this. It has moved from being a fatal to a chronic illness, thanks to the development of new drugs, but no one could have predicted that change with certainty ten years ago. What if, in Raanan's experiment the apparently beneficial effect of the modification merely opens the door to a more virulent disease several generations ahead? (We cannot be sure that prior animal experiments would rule that out.)

So what might we conclude from this? I would argue that human flourishing is such a fragile and altering phenomenon that it would be wrong to try to "fix" the welfare of future generations. The VE approach accepts limits on our powers as humans and stresses equanimity in the face of human mortality and vulnerability. This does not mean that VE endorses passivity in the face of remediable suffering-it is not against the progress of science and medicine. But it emphasises the acceptance of our human condition and sees the challenge to be one of living within the boundaries of our knowledge and our capacity to make clear improvement. So I am arguing unashamedly for the precautionary principle and for a continued ban on germline modification. But I am unsure if such a conservative view needs a VE backing at all. It seems to me to be there already in any approach to technology, which gives genuine weight to the principle of primum non nocere. Principlists should also be precautionists!

\section{CONCLUSION}

Let me repeat what I said at the outset. This is not an attempt to supplant principlism, and to put virtue ethics in its place as the dominant theory in medical ethics. I am happy to concede the greater usefulness of the four principles in some of the scenarios suggested by Raanan. This approach can have more analytical force than virtue ethics in some of the standard cases which medical ethics considers. But the vice of principlism is its tendency to claims greater than it can justify. It points in the direction of solutions to some of our dilemmas-for example, by suggesting we calculate the benefit/burden ratio, but it is far from providing enough conceptual apparatus for making these difficult judgments. We need a diversity of approach in these complex human scenarios, and no theory should be seen as dominant. I imagine Raanan would agree with this in principle, but still a note of imperialism seems to creep into his writings! We are left with the feeling that, given scope, principlism can account for all our moral worries. This, if it is what he implies, is just plainly wrong. We need an account of character, not just of right and wrong decisions, in order to give a full account of the moral life. For all its difficulties, I have been arguing than VE provides insight into this essential dimension of medical ethics. So perhaps both approaches need some magnanimityand a lot of humility!

\section{REFERENCES}

1 Campbell AV, Swift T. What does it mean to be a virtuous patient? Scottish J Health Care Chaplaincy 2002;5:29-35.

2 Gillon R. Four scenarios. J Med Ethics 2003;29:267-8.

3 Statman D, ed. Virtue ethics: a critical reader. Edinburgh: Edinburgh University Press, 1997: introduction.

4 Crisp R. How should one live? Essays on the virtues. Oxford: Clarendon Press, 1996.

5 Plato. Apology. The last days of Socrates [translated by Tredennick H, Tarrant H]. London: Penguin, 2003.

6 Bellah RN, Neeley R. Habits of the heart: individualism and commitment in American life. Berkeley: University of California Press, 1985.

7 Campbell AV. Health as liberation. Cleveland, OH: Pilgrim Press, 1995.

8 Gillon R, Lloyd A, eds. Principles of health care ethics. Chichester: Wiley, 1994: xxii.

9 Maclntyre A. After virtue. London: Duckworth, 1985

10 Beauchamp TL, Childress TF. Principles of biomedical ethics [4th ed]. New York: Oxford University Press, 1994: 69

11 Nussbaum M. Non-relative virtues: an Aristotelian approach. In: French $\mathrm{P}$, Uehling TE Jr, Wettstein HK, eds. Ethical theory, character, and virtue. Notre Dame: University of Notre Dame Press, 1988.

12 Campbell AV. The "ethics of care" as virtue ethics. In: Evans M, ed. Advances in bioethics [vol 4]. London: JAl Press, 1998: 295-305.

13 Gillon R. Refusal of potentially lifesaving blood transfusions by Jehovah's Witnesses: should doctors explain that not all JWs think it's religiously required? [editorial]. J Med Ethics 2000;26:299-301.

14 Murray TH. Gifts of the body and the needs of strangers. Hastings Cent Rep 1987;17:30-8 at 37 